\title{
The Multipath Approach to Personality: Towards a Unified Model of Self
}

\author{
Jonathan Appel ${ }^{1}$, Dohee Kim-Appel ${ }^{2}$ \\ ${ }^{1}$ Tiffin University, Department of Behavioral and Social Sciences, Tiffin, USA; ${ }^{2}$ Firelands Counseling and Recovery Services, Tiffin, \\ USA. \\ Email: jappe137@yahoo.com
}

Received May $21^{\text {st }}, 2010$; revised June $3^{\text {rd }}, 2010$; accepted August $30^{\text {th }}, 2010$.

\begin{abstract}
Human beings exist in multiple substrates or dimensions. But we still need more comprehensive and integrative theories of self-identity and personality. Most personality and developmental theories fail to adequately address the interaction among the psychological, interpersonal, environmental, and biological aspects of self and personality development. This paper presents a larger framework in which to examine prior models of personality as well as future integrative models. A Multipath Approach to Personality (MAP) is proposed and consists of the following dimensions or levels of analysis of self: 1) the Neuropersonal; 2) the Intrapersonal; 3) the Interpersonal; 4) the Exopersonal; 5) the Ecopersonal; and 6) the Transpersonal. The MAP approach to personality also suggests a multi-modal practice in assessment and research.
\end{abstract}

Keywords: personality Theory, Systems Theory, Interdisciplinary Approaches, Transpersonal Psychology

\section{Introduction}

According to Millon [1] most personality theories fail to adequately address the interaction among the psychological, interpersonal, environmental, and biological aspects of personality development. Therefore, Millon [1,2] together with a number of other critics - such as Church, [3], Endler, [4], Schultz \& Schultz, [5], and Laher, [6] all argue that most current theories provide a less than comprehensive perception into an individual's personality and identity and suggest that a more holistic and integrated approach to personality is still needed. The Multipath Model presented in this paper is an attempt at an integrative and interacting model for viewing personality and psychological development.

\subsection{Towards an Interdisciplinary and Systemic View of the Self}

Human beings exist in multiple substrates. Scholars have been and are currently working on more comprehensive and integrative theories of self-identity and personality. Humans are indeed at least bio-cultural beings. We are neither biologically determined, nor tabula rasa, upon which culture is imposed. Rather, identity and personality organization emerge out of a jointly active and dynamic process. Models with these views describe holistic epistemologies which attempt to reflect this complex ontology and thereby avoid reductionism.

Certainly the biopsychosocial model as articulated by Engels [7] and Bronfenbrenner's bioecological systems theory [8] both seek to move beyond linear and reductionist views of health and development. Engels argues that scientific and inclusive account of health and illness should utilize the insights of general systems theory in which there are levels of organization from lower to higher. Systems models of organized hierarchies contain lower levels of organization which are necessary for higher ones to exist but would not be sufficient to describe or explain their nature. With each higher level of organization emergent qualities appear which are not present at lower levels. Thus to Engels, physical and mental health are not merely a singular biological or an emotional process but a spiral of physical, psychological, and social ordering that is intertwined in a complex relationship. Bronfenbrenner's bioecological systems theory also attempts a similar larger view of human development within the context of systemic levels of relationships (microsystem, mesosystem, exosystem, macrosystem, and chronosystem) that form one's environment. Bronfenbrenner emphasizes that while a child's own biology is a force fueling his/her development - the interaction between factors in the child's maturing biology, 
his/her immediate family/community environment, and the societal landscape drives and steers his/her development. While the Biopsychosocial and bioecological systems model has been given a fair amount of "lip-service" in medicine, psychiatry and other mental health fields, these models have failed to make a real transformative impact. Pilgrim [9] contends that despite the professional, scientific and ethical virtues of systemic models in mental health, the promise of these models have not been fully realized and have been kept in the shadows by a return to medicine and the reascendancy of a biomedical model or biology as the primary force underlying psychological development.

But there are additional models in the mental health literature that contend that psychological concepts cannot be reduced to mere biological correlates. These models suggest the psychological is reciprocally connected to the biological processes but coalesce with different and emergent interdependent properties. An example of this is the multi-layered systemic consciousness-based model of the psyche proposed by Douglas Hofstadter [10]. Hofstadter formulates a three-level model of the self. He suggests the human psyche is based on a kind of strange loop, an interaction between levels in which the top level reaches back down towards the bottom level and influences it, while at the same time being itself determined by the bottom level. Based on Gödel's paradox, Hofstadter offers structures in which a new level of meaning could "speak about" a lower level of meaning via a higher-order, nested structure. The model suggest "non-material' thoughts and identity arising out of material neurons and electrochemical reactions-creating the symbolic "I" that is maintained and modified by the feedback of the external world. The outcome is still paradoxical and self-referential but it is offered as a more accurate picture of how the mind works. Similarly, Damasio [11] also suggests that we are made up of at least three selves (proto-self, core-self, and autobiographical self) - each corresponding to a layer of consciousness whose characteristics and neural correlates can be identified. More recently, Peck [12] also proposes a multilevel systems theory applied to a person-in-context approach. Functionally nested levels are used to distinguish personal identity from sense of symbolic belief from iconic schema systems. Peck hypotheses a contextualized identity model where levels of integration unfold separately, but interdependently across levels of representations.

Indeed, there have been a few theorists/theories that are moving toward a multidimensional view and the recent advances in neuroscience research may spark a renewed interest in a multidimensional and interactional view. In fact, whole new sub-fields that have been called
Interpersonal Neurobiology and/or Social Neuroscience have emerged as a means to integrate and connect the recent advances in neurological and brain data with social and behavioral correlates [13]. Sue, Sue, and Sue [14] present a view that includes biological, psychological, social and cultural dimension or multiple paths towards mental disorder but their view only focuses on pathology. While all these multilevel models have been more systemic and attempt to account for an interaction of influences - they still often fail to adequately account for the influence of processes at all possible levels or domains of self. The assumption of the Multipath Approach to Personality (MAP) model includes the notion that personality and self are shaped by the combined forces of evolutionary, biological, situational, mental, as well as a psycho-spiritual processes - all embedded in a temporal, socio-cultural, and developmental context see Figure 1. It is assumed one can use various levels of analysis in the description of psychological functioning, and no one level would be the complete or accurate description. But taken together all levels provide an additive view that constructs a wider and clearer lens for viewing human personality and psychological development of the self.

\section{The Multipath Approach to Personality (MAP)}

The Multipath Approach to Personality (MAP) consists of the following dimensions or levels of analysis of the self: 1) the Neuropersonal; 2) the Intrapersonal; 3) the Interpersonal; 4) the Exopersonal; 5) the Ecopersonal; and 6) the Transpersonal.

\subsection{The Neuropersonal Self}

One level of analysis can be thought of as the "neuropersonal" level of self. Through this lens human beingsare viewed as biological and evolutionary organisms. This level is focused on biological-genetic-material func-

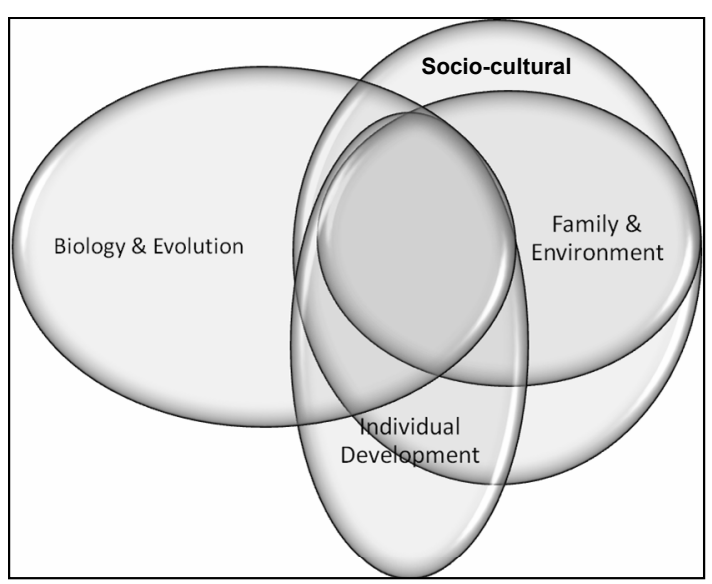

Figure 1. Domains of influence in personality development. 
tioning, and also represents the "pre-personal" field. From this perspective the individual can be primary described as driven by biological mechanisms. Mental processes are seen objectively through a biological lens within the organism, with genetic makeup playing an important role in the development or maintenance of personality and some abnormal conditions. Personality can be seen as influenced by temperament-which are biologically based characteristics apparent in early childhood and establish the tempo and mood of an individual's behaviors. Autonomic nervous system reactivity may be inherited. Differences in personality arise from balance of neurotransmitters, but also can be shaped by learning. Neuroscientists and evolutionary psychologists suggest that our "reptilian brain" influences personality and basic drives of sex, aggression, hunger, thirst and basic survival. It is the prerational world of Freud's Id and the lower survival (deficiency) needs mapped by Maslow [15]. Its influence is often below ego awareness and functions unconsciously or pre-consciously.

Our behavior as influenced by this domain is often focused by individual and evolutionary life force - safety and survival. This primal self seeks to hold off threat against the forces of the world in service of the prime objective of life, or Dawkins" "selfish" gene directive of survival and replication [16]. Our perceptual systems and deep biological functioning have been organized around two functions - 1) determine which environmental stimuli pose a threat to our existence - who is 'safe' or "like us" and who is "the different one" (in group vs. out group) and 2) replicate our genetic material. These are the realms of the lower and mid-brain regions with its biological and emotional processes - programmed through evolutionary and genetic forces to aid our physical survival and propagation. Our very biology and behavior mapped from DNA carries the desire to stay alive and protect the self-system. Our Neuropersonal level also includes the evolution of our paleo-mammal brain (as the origin of consciousness) and is built upon the unique properties of the mammalian neocortex. But even in our developed brain functions is the inherent tendency of limbic and admygdala activation (fear and aggression) - which still often take precedence to the more recent frontal cortical emergence in human evolution.

Of course Western science still often has the "bottom-up" tendency to view human development merely as biological determinism - in a linear way. But the reality of human behavior is far more complex, and has multiple reciprocal influences. Studies show environment affects biochemical and brain activity, as well as structural neurological circuitry [17]. Science increasingly rejects idea of "one gene for one disease." Gene-environment interactions appear more complex than simply having a "pre- disposition" [18]. Studies reveal different forms of same genes interacting with critical development periods in life of individual may determine when, how, and what mental illness occurs [19]. Evolutionary shifts are always occurring in all our systems - both personally and at higher levels of organization of the self. Living systems while rooted in the biological are also as increasingly influenced by larger levels of organized development.

\subsection{The Intrapersonal Self}

The intrapersonal level of self is the psychological and the mental field. This is the realm of self staked out by ego and cognitive psychology and its intellectual descendants. It is at this level we then began to give way to an increasing sense of separation from the whole, with an accompanying, growing sense of individual self-consciousness and self-identity beginning to develop.

The intrapersonal level has its focus on the "information stored about the self" and the cognitive perspective of personality and the idea that people are who they are because of the way they think, including how information is attended to, perceived, analyzed, interpreted, encoded and retrieved. People tend to have habitual thinking patterns which are characterized as concepts of self and personality. One's identity and personality, then, would be characteristic of one's cognitive patterns. This is suggestive that considerable capacity for personality change and mental health with an altering of thinking patterns.

From this perspective psychological function can also be localized into the "Big Five" traits. The Five-Factor Model (FFM) is an empirically supported personality model that specifies that most stable individual differences in emotions, cognition, and behavior can be described by five independent domains: Neuroticism, Extraversion, and Openness to Experience, Agreeableness, and Conscientiousness.

These 'traits' are seen through the intrapersonal lens as residing within the personal (but may be expressed at other levels) and are empirically related to individual personality and overall global stability. Research shows that the five-factor structure of personality in some sense transcends language/culture and may indeed be universal [20]. The Big Five structure does not imply that personality differences can be reduced to only five traits. Rather, these five dimensions represent personality at the broadest level of abstraction, and each dimension summarizes a large number of distinct, more specific personality characteristics [21]. The intrapersonal level is also reflected within Freud's concept of ego, and Jung's concept of ego and persona. It is the most "visible" aspect of individuals, and is reflected in cognition and in the development (or lack) in an integration of rational and emotional functions (similar to the concept of differen- 
tiation of self-see Bowen [22]).

Cognitive styles as viewed from the intrapersonal level can be seen as being organized around the before mentioned five traits. For example, a person develops a cognitive "self schema" other "person schema" around one's own traits. Those individuals who score high in Neuroticism develop cognitive structures that explain and reinforce their emotional reactivity (e.g. people aren't to be trusted). Individuals with high conscientiousness would operate by a very controlled rule based cognitive structure. Poorly individuated people would develop constant threat-based cognitive schemas (and score low in the openness trait). Personality and cognitive schemas are also represented in the Jungian archetypes, by which one either identifies or disowns archetypes as a reflection related to their self system and traits. For example, the degree in which we project our shadow content would be related to our level of neurosis. Traits, like archetypes are biologically grounded, and express themselves within the context of the emergent conscious ego and cognitive structures. But the content of the intrapersonal is driven by the submerged or deep self and the simultaneous desire and fear to come into true contact of all knowledge about oneself. The ego can represent the wall or the bridge to this inner deep self. Subsequent levels in this model may be viewed as the expression of this deeper with a more expansive sense of a self-system. Growth and adaptation would be measured by the consistent attainment of the ability to achieve and maintain a sense of psychological safety, in which one is safe to expand the self system. Once sufficient physical and psychological safety needs have been at least partially satisfied, both Rogers and Maslow identified that the individual actualizing tendency would be released, as people would be motivated to meet not only biological needs, but also the growth needs of the self [23]. Once this developmental mechanism is enacted - one would seek to move towards self-actualization, which is the inherent tendency to strive toward realization of one's full potential (an expansion of the self system). But trauma and unresolved trauma can lead to lasting patterns of hyperarousal, dissociation, negative cognitions, and can thwart expansive growth.

\subsection{The Interpersonal Self}

The interpersonal level of self is the social and family relationship field. Healthy Relationships are important for human development and functioning, with personal and family relationships providing many intangible healthy benefits, and feedback and identity to the selfsystem. When relationships are dysfunctional, individuals may be more prone to abnormal behavior and/or mental disturbances. Personality disorders generally re- flect a maladaptive (self-defeating) interpersonal pattern (see [24-31]). At this level of analysis personality development can also be viewed as being influenced by family attributes and dynamics as well as attachment. Abnormal behavior is a reciprocal reflection of unhealthy family dynamics and poor communication. While this domain is manifested at the social level-relationships and multigenerational relational patterns can over time impact biological adaptation or maladaptation., Studies do show environment can influence biochemical and brain activity, as well as structural neurological circuitry [19], and perhaps even genetic evolution over the long expanse of a multi-generational repetition compulsion in how one relates to others. Families serve as the formative environment for relationship blueprints, that impact interpersonal dynamics which are reflected in other levels of organization, including the work environment (see [32]). Interpersonal patterns and the interpersonal self can provide an impetus to an expansive or a restrictive self, depending on the health of these relationships.

\subsection{The Exopersonal Self}

The exopersonal level of self is the cultural-societal aspect of the self system. This level acknowledges that human personality development arises from particular socio-cultural contexts. This level suggests that some sociocultural stressors reside within the social systemnot within the person (but are expressed at other levels, including the interpersonal and intrapersonal level). This level of analysis recognizes assumptions people make vary widely across cultures - depending especially on whether the culture emphasizes individualism or collectivism. A particular sociocultural development is one factor that would lead to different brain expression/development and social learning particular to our culture (cultural relativism), while we might be the same on some traits and behaviors (cultural universality). It would be at exopersonal level that Adler's concept of social interest [34] could be reflected and could be used as a measure of development at this level. The exopersonal represents a higher level of interaction with the other-in that the interpersonal level represents actually immediate relationships and represents our conceptual relationships with people and groups not known personally and our expression of altruism towards them. Health of the exopersonal self has implications for the health of the community and vice versus.

\subsection{The Ecopersonal Self}

This is the global-planetary field of self (Gaia), which is "post-personal". This level represents our "ecological consciousness." It is how we see ourselves, our egos, in relationship to the planet and the natural world as a 
whole. Eco-psychology represents a new sub-discipline that studies individuals within this context. Development at this level would be marked by a sense and a more interconnected whole of all living processes on the planet. Our sensing and sense of self would be expanded at this level. Larger organizational principles and meaningful connections and patterns would be emerging as outlines of something larger than the individual self. Both Sewall [35] and Bernnan [36] see as humanity as progressing through a stage of evolution where we have developed a personal self that is separate from the natural world and as a result of the self-conscious ego (with culture specific difference needs on independence and achievement). The ecopersonal level suggests the call to enter the next stage, a transpersonal shift towards recognition of the possibility of development towards a "unity consciousness." Unity consciousness can be described as the ability to transcend opposites, to recognize and integrate complex relationships (going from parts to wholes), and to embrace all experience in the living world equally and unconditionally. The ecopersonal self marks the sense of the increasing expanded sense of health and functioning.

\subsection{The Transpersonal Self}

At the transpersonal level is the emerging collectiveunity consciousness, as well as acknowledgement of the nearly universal need for the spiritual dimension of the human psyche. Religious and Spiritual traditions across cultures and epochs have traditionally focused on the transpersonal accepts of living, but as psychological science evolves, there may be a recognition and the need to study this transpersonal level of self. This domain represents the need for an "expansive" identity beyond the personal ego and the desire to experience "transrational" stages of consciousness (see [37]). The transpersonal domain represents the integration of all forms and functions of other MAP levels, but also transcends them. Transpersonal psychology notes although identity and personality exists on the plane of sense-con-sciousness - one can develop the conscious psychological ego to where it becomes like a thin line-with just sufficient individuality to retain contact with the everyday reality of existence but also holding a larger connecting "spiritual" or transpersonal view. This meta- perspective enables one to see one own true self, but also as psychological understanding that all part of a whole unification (or a "One") - manifesting itself in different forms. The psychological study of peak experiences (see [38]) and flow (see [39]) examines some of this territory and its relation to the psyche and human development, but much of this domain remains under examined within the field of psychology. Although transpersonal psychology has produced relatively little quantitative research, the recent empirical verification of mindfulness as an important construct in mental health represents a feature of transpersonal consciousness beyond the normal sense of individual self experience. Recent empirical support for the metapersonal self-construal in psychological functioning also suggests that the transpersonal identity may be a future untapped and potentially fertile area for psychology and personality theory (see [40]).

Each level or domain in the MAP represents different views of personality and development and each has supporters who are influenced by their models. Greatest understanding comes from integrating approaches. It is all embedded systems, in which the parts also influence the whole isomorphically_see Figure 2.

\section{Interaction of the MAP Levels: Aggression}

With the implied interdisciplinary and multidimensional approach of the MAP model let's now examine an example of aggressive behavior and an aggressive personality pattern through each level.

\subsection{Aggression at the Neuropersonal}

At the neuropersonal level, brain region of the amygdala is highly relevant and highly implicated in viewing aggression (as well as malfunctioning of the limbic and prefrontal cortex). Studies have consistently found that deficits in certain neuropsychological functions correlate with aggressive personality, impulsivity, and other forms of persistent, serious misconduct. Prefrontal lobe damage

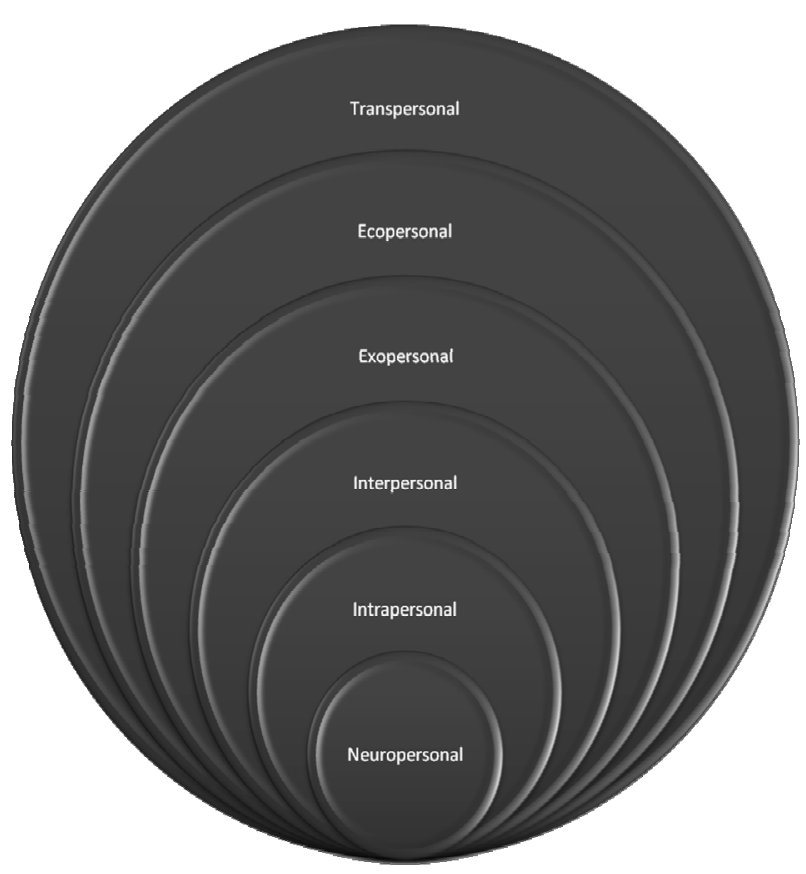

Figure 2. MAP model. 
has been reported in $73 \%$ of subjects with a history of violent crimes compared with $28 \%$ of those with no such damage [41]. Studies that use neuroimaging assessment (e.g., PET, fMRI) have found diminished brain activity in the pre-frontal cortex in individuals with persistent violent behavior [42]. Research in antisocial and aggressive behavior; have also consistently reported low cortisol responses in psychopathic criminal offenders [43] and in boys with aggression or at high risk for substance abuse [44-46]. Such deficits are considered to reflect an underarousal of neuro-circuitry in the emotional systems that help regulate behavior. Sources of damage to neural circuits that may disrupt ability to assess consequences and regulate impulses include head injury, prenatal drug exposure, neurotoxins, childhood deprivation, and chronic drug use. Aggression in part, is often seeded in the neuropersonal, but will take deep root if watered by other pathways.

\subsection{Aggression at the Intrapersonal}

It has long been recognized that cognitions as well as individual constructions of reality play an influential role in behavior and emotions, including anger and aggression. Many cognitive and Information-processing models of aggression have emerged in the literature (see [47-49]). Although these models vary in terminology and focus, the models all suggest similar premises about aggression as being influenced by social-information and problem solving structures and highlight the interaction between cognition, emotional arousal, and rigid behavioral and personality types - which are reflected in the intrapersonal domain.

\subsection{Aggression at the Interpersonal}

The Interpersonal level recognizes we have developed organized aggression at the level of the social band. We can communicate aggression towards others with even an abstraction over space and time. Although aggression and anger has biological aspects, its expressions are learned from social experiences. Maladaptive anger is one of many coping strategies learned from families during childhood experiences. Allen Schore [50] has outlined in exquisite detail the psychobiology of early childhood development involving maturation of orbitofrontal and limbic structures, but also suggests this is mediated by reciprocal experiences with the caregiver, which can have lasting impact. Research does recognize that aggressive, antisocial, and impulsive acts are often associated with abusive and neglectful childhoods as well as from a social learning process, which seems to be associated with some of the most extreme forms of behavior in the current discussion. Other theories held that the drives instigating interpersonal aggression were situ- ated in the environment and were stimulated by frustration. This theory is best known as the frustration-aggression hypothesis. These theories propose that people are aggressive toward others when their goals are interfered with, especially when the anticipated goals included anticipated pleasure [51]. Modern research in aggression and aggressive personality types continues to be influenced by the interpersonal theories of aggression.

\subsection{Aggression at the Exopersonal}

Exopersonal level represents our conceptual relationships with people and groups not know personally and our expressions towards them. This is both the human construction of social networks and culture as well as the newer rapid expansion of the technology-centered social systems. Some have observed that technology and society have become completely interwoven. This can have a profound impact on identity and personality. While access to a larger and more diverse cultural and social world has great potential for expanding knowledge of self and the world, one may question whether this is always good. The incidence of Attention Deficit Disorder (ADD), Attention Deficit Hyperactivity Disorder (ADHD), and Autism has been increasing and perhaps this trend also represents an increasing dysfunction at the societal-technological level. That is not to say that these issues do not have a neurological basis-but perhaps represent a neuropersonally vulnerable condition that is shaped and expressed more readily in the current interpersonal, social, and environmental conditions that technological societies are now experiencing. Localized human group connections and sustained interactions are being replaced by superficial interaction and functioning in simulated and expanding electronic social worlds with increasingly rapid interaction and mental processing. The breadth of self-other interaction is expanding greatly but often in exchange for human depth. There is research demonstrating that adolescents with internet addiction had higher ADHD symptoms, but also increased associations with depression, hostility, and aggressive behaviors [52]. In systems theory children are often viewed as symptoms bearers for larger interpersonal and exopersonal dysfunctions (and perhaps even ecopersonal and transpersonal). The human organism has an innate and instinctual drive towards growth, social connection, and wholeness, particularly seeded by nurturing human relationships. But what happens if these relationships are absent or disturbed or displaced in a new excopersonal environment? Does an increase in social interaction and information volume have a cost? Does this social and technological overload get transmuted into symptoms and even in the biology of our children? Is the rise of child mental health problems a result of more sensitive 
diagnostic systems or a warning signal that our families and communities and environments levels are also in distress? The exopersonal level is often overlooked or minimized in the current etiological theories of aggression.

\subsection{Aggression at the Ecopersonal}

Being connected and feeling part of the natural world also has implications for the health of a person. Evidence has demonstrated that just by viewing nature many aspects of human health and development can be markedly improved. In a review of the literature, Rohde and Kendle [53] found that the psychological response to nature involves feelings of pleasure, sustained attention or interest, "relaxed wakefulness", and reduction of negative emotions, such as anxiety and anger.

The ecopersonally developed person recognizes the escalating spread of pain and despair being felt by people in response to nature's continuing destruction. Violence against the earth is perhaps a reflection of unresolved fear and aggression in the human psyche. The idea is that personal health and planetary health are connected and as Anthony Stevens has remarked, "The unconscious is nature, but we have to confront its contents if we are to become conscious of them" (Stevens [54], p. 34). The health of natural world is connected to the health of organisms that reside within in. Healing of the earth will result in healing of the individual and vice versa. Sickness in the health of the natural world will be expressed in the most vulnerable of its inhabitants. Aggression in the ecopersonal self could have implication both personally and planetary.

\subsection{Transpersonal Roots of Aggression}

It is at the transpersonal sphere of influence one can be driven towards aggressive acts. It is from this level one can express what Grof [55] calls "malignant destructiveness". Grof indicates the need to distinguish "defensive" or "benign aggression" which is in service of the (perceived) survival of the individual or the species. But "Malignant destructiveness" is a form of aggression that can be done with even without any biological or economic reasons. "Malignant destructiveness" is born out a lack of a transpersonal perspective (e.g. experiencing a discontinuity among living organisms) as well as in a striving for transcendence in the context of desiring death-rebirth. This search can be worked through in a constructive moral and ethical system or it can be abandoned in despair and/or existential crisis. This mystical quest and innate desire for purpose, meaning, and transcendence beyond a finite material life can also be perverted or hijacked by spiritual or religious systems that advocate self or other destruction. This can be seen in the mass suicide of the Jim Jones cult or in the acts of the religious suicide bomber that is acting on promises of a grander existence after death. Thus, the underdeveloped or maladaptive transpersonal self can have dire implications in guidance of behavior.

\subsection{Putting the Paths Together}

It now appears likely the most aggressive personalities are created by a malignant combination of the dysregulated brainstem functions (e.g., anxiety, impulsivity, poor affect regulation, motor hyperactivity) sensitized brainstem systems (e.g., serotonergic, noradrenergic and dopaminergic systems) and experiences that include developmental neglect and traumatic stress during childhood. Urban and nature-deprived environments also provide a particularly fertile ground for incubation and expression of aggressive prone individuals. The interpersonal and the exopersonal can be seen as environmental levels that provide both external triggers of aggression and provide the stage for expression of the intrapersonal and neuropersonal elements associated with aggression.

The most aggressive prone individuals are characterized by poorly organized limbic and cortical neurophysiology and poorly modulated by intrapersonal psychological-cognitive functions (e.g., empathy, problemsolving skills) which are the result of chaotic, undersocialized development, resulting in continuing interpersonal functioning and a disconnection from natural world (ecopersonal) around them as well as a void or hijacking of higher moral and transpersonal development. This experience-based imbalance and reciprocal neuropersonal and cognitive functioning can result in a host of mental health problems and aggressive/violent behavior with a disconnection from the realms of the ecopersonal and transpersonal. This is then reflected as a restrictive sense of self-a person who risks little and is often ready to attack others in a defensive posture based on symbolic cognitive structures that perceive the world as a hostile and isolated place.

The MAP levels offer an interactive and holistic dynamic for development and expression of human functioning-but some behavior and identity formation may be represented by a "factor-loading" at a certain level. That is to say that some expressions of a behavior and a personality may be driven by a certain level(s). Certainly the neuropersonal may provide a potent source for personality based on genetic and neurological breakdown which can be reciprocally amplified by early interactions and environmental experiences. Other personality and identity issues may be driven by intrapersonal aspects (e.g. poor psychological development interacting with interpersonal experiences) or excopersonal or transpersonal maladaptation. All levels influence and interact with each other in a kind of positive feedback loop and rein- 
force each other. Changes or conflict in any one layer will ripple throughout other layers. To study personality development then, we must look not only at the person and her immediate environment, but also at the interaction of the larger domains as well.

Further research needs to be down to tease out the different domain interactions and how they express themselves idiosyncratically. The MAP approach also has implications for assessment and treatment, suggesting that a full multiple level view and targeted multiple level interventions would be required.

\section{Conclusions}

This paper was a rough attempt to develop a larger framework in which to examine prior models of personality as well as future integrative models. The MAP approach to personality is also suggestive of a multi-modal practice of personality assessment and research. As C.H. Waddington [56] points out: "there is congruity between our apparatus for acquiring knowledge and the nature of the things known," (p. 36). Typically, we have the tendency to approach the challenge of understanding our minds categorically through a narrow lens. Categorical thinking while developmentally has helped our thinking (e.g. helps understand and encode information in our memory) - it also distorts our ability to see the differences and similarities between two different facts or concepts. If you pay too much attention to the boundaries, you have trouble seeing the big picture.

Whether in research or assessment of personality one should be collecting "holistic" multi-method data. The examination of this data should also take both the objective (empirical-behavioral-external) view-as well as the "subjective" (internal-qualitative narrative) view in account. One dimensional assessment can be helpful, but never should be used as the only piece of information. Human beings and human personality exist on multiple levels and thus should be assessed on those levels. In the future, the most influential theories will be those that adopt a multipath approach in which factors from different approaches are coherently linked. Our theoretical, research, and data collection models need to capture and reflect this complexity.

\section{REFERENCES}

[1] T. Millon, "An Integrative Theory of Personality and Psychopathology," In: T. Millon, Ed., Personality and Psychopathology: Building a Clinical Science, Wiley, New York, 1996, pp. 59-70.

[2] T. Millon, "Millon Index of Personality Styles Manual," The Psychological Corporation, Orlando, 1994

[3] T. Church, "Culture and Personality: Toward an Integrated Cultural Trait Psychology," Journal of Personality,
Vol. 68, No. 4, 2000, pp. 651-704.

[4] N. Endler, "Personality: An Interactional Perspective," In: J. Hettema and I. Dreary, Eds., Foundations of Personality, Kluwer Academic, Netherlands, 1993, pp. 251-268.

[5] D. Schultz and S. Schultz, "Theories of Personality," Pacific Grove, CA, Brooks/Cole, 1994.

[6] S. Laher, "Personality Reconceptualised: A Millonian Approach?" South African Journal of Psychology, Vol. 37, No. 1, 2007, pp. 82-95.

[7] G. Engel, "The Clinical Application of the Biopsychosocial Model," American Journal of Psychiatry, Vol. 137, No. 5, 1980, pp. 535-544.

[8] U. Bronfenbrenner, "The Ecology of Human Development: Experiments by Nature and Design," Harvard University Press, Cambridge, 1979.

[9] D. Pilgrim, "The Biopsychosocial Model in Anglo-American Psychiatry: Past, Present and Future," Journal of Mental Health, Vol. 11, No. 6, 2002, pp. 585-594.

[10] D. Hofstadter, "I am a Strange Loop," Basic Books, New York, 2007.

[11] A. Damasio, "The Feeling of What Happens," Random House, London, 1999.

[12] S. Peck, "TEMPEST in a Gallimaufry: Applying Multilevel Systems Theory to Person-in-Context Research," Journal of Personality, Vol. 75, No. 6, 2007, pp. 11271156.

[13] D. Siegel, "Toward an Interpersonal Neurobiology of the Developing Mind: Attachment, Mindsight, and Neural Integration," Journal of Infant Mental Health, Vol. 22, No. 1-2, 2001, pp. 67-94.

[14] D. Sue, D. W. Sue and S. Sue, "Understanding Abnormal Behavior," 9th Edition, Wadsworth, Boston Mass, 2010.

[15] A. Maslow, "Motivation and Personality," Harper, New York, 1954.

[16] R. Dawkins, "The Selfish Gene," Oxford University Press, New York, 1976.

[17] E. Kandel, "Psychiatry, Psychoanalysis, and the New Biology of Mind," American Psychiatric Publishing, Arlington, 2005.

[18] E. Wilson, "Sociobiology: The New Synthesis," Harvard University Press, Cambridge, 1975.

[19] P. Baltes, P. Reuter-Lorenz and F. Rosler, "Lifespan Development and the Brain: The Perspective of Biocultural Co-constructivism," Cambridge Univiersity, Cambridge, 2006.

[20] R. McCrae and A. Terracciano, "Universal Features of Personality Traits from the Observer's Perspective: Data from 50 Cultures," Journal of Personality and Social Psychology, Vol. 88, No. 3, 2005, pp. 547-561.

[21] O. John and S. Srivastava, "The Big Five Trait Taxonomy: History, Measurement, and Theoretical Perspectives," In: L. Pervin and O. John, Eds., Handbook of Personality: Theory and Research, 2nd Edition, Guilford Press, New York, 1999, pp. 102-139.

[22] M. Bowen, "Family Therapy in Clinical Practice," Jason 
Aaronson, New York, 1978.

[23] R. DeCarvalho, "The Founders of Humanistic Psychology," Praeger Publishers, Westport, 1991.

[24] L. Benjamin, "Interpersonal Diagnosis and Treatment of Personality Disorders," Guilford Press, New York, 1996.

[25] R. Carson, "Interaction Concepts of Personality," Aldine, Chicago, 1969.

[26] D. Kiesler, "Contemporary Interpersonal Theory and Research: Personality, Psychopathology and Psychotherapy," Wiley, New York, 1996.

[27] T. Leary, "Interpersonal Diagnosis of Personality," Ronald Press, New York, 1957.

[28] C. McLemore and D. Brokaw, "Personality Disorders as Dysfunctional Interpersonal Behavior," Journal of Personality Disorders, Vol. 1, 1987, pp. 270-285.

[29] A. Pincus and J. Wiggins, "Interpersonal Problems and Conceptions of Personality Disorders," Journal of Personality Disorders, Vol. 4, No. 4, 1990, pp. 342-352.

[30] H. Strupp and J. Binder, "Psychotherapy in a New Key: Time Limited Dynamic Psychotherapy," Basic Books, New York, 1984.

[31] H. Sullivan, "The Interpersonal Theory of Psychiatry," Norton, New York, 1953.

[32] J. Appel and D. Kim-Appel, "Families at Work: The Relationship between Family Coping and Employee Burnout," The Family Journal: Counseling and Therapy for Couples and Families, Vol. 16, No. 3, 2008, pp. 231-239.

[33] A. Adler, "Social Interest: A Challenge to Mankind," Faber and Faber Ltd. London, 1938.

[34] L. Sewall, "Sight and Sensibility: The Ecopsychology of Perception," Jeremy P. Tarcher/Putnan, New York, 1999.

[35] C. Brennan, "The Personal is Planetary," In: D. Firman, and D. Klugman, Eds., Reflections on Ecopsychosynthesis, AAP Monograph, Association for the Advancement of Psychosynthesis, Amherst, 1999.

[36] R. Walsh and F. Vaughan, "On Transpersonal Definitions," Journal of Transpersonal Psychology, Vol. 25, No. 2, 1993, pp. 125-182.

[37] A. Maslow, "Religion, Values and Peak Experiences," Viking, New York, 1970.

[38] M. Csíkszentmihályi, "Flow: The Psychology of Optimal Experience," Harper and Row, New York, 1990.

[39] T. DeCicco and M. Stroink, "A Third Model and Measure of Self-Construal: The Metapersonal Self," International Journal of Transpersonal Studies, Vol. 26, 2007, pp. 82-104.

[40] E. Bryant, M. Scott, C. Golden and C. Tori, "Neuropsychological Deficits, Learning Disability, and Violent Behavior," Journal of Consulting and Clinical Psychology, Vol. 52, No. 2, 1984, pp. 323-324.

[41] P. Goyer, P. Andreason, W. Semple, A. Clayton, A. King, B. Compton-Toth, S. Schulz and R. Cohen, "PositronEmission Tomography and Personality Disorders," Neu- ropsychopharmacology, Vol. 10, No. 1, 1994, pp. 21-28.

[42] A. Raine, "The Psychopathology of Crime: Criminal Behavior as a Clinical Disorder," Academic Press, New York, 1993.

[43] M. Dawes, L. Dorn, H. Moss, J. Yao, L. Kirisci, R. Ammerman and R. Tarter, "Hormonal and Behavioral Homeostasis in Boys at Risk for Substance Abuse," Drug and Alcohol Dependence, Vol. 55, 1999, pp. 165-176.

[44] K. McBurnett, B. Lahey, P. Rathouz and R. Loeber, "Low Salivary Cortisol and Persistent Aggression in Boys Referred for Disruptive Behavior," Archives of General Psychiatry, Vol. 57, No. 1, 2000, pp. 38-43.

[45] H. Moss, M. Vanyukov, J. Yao and G. Kirillova, "Salivary Cortisol Responses in Prepubertal Boys: The Effects of Parental Substance Abuse and Associated with Drug Use Behavior during Adolescence," Biological Psychiatry, Vol. 45, No. 10, 1999, pp. 1293-1299.

[46] N. Crick and K. Dodge, "A Review and Reformulation of Social Information-Processing Mechanisms in Children's Social Adjustment," Psychological Bulletin, Vol. 115, No. 1, 1994, pp. 74-101.

[47] C. Anderson and K. Dill, "Effects of Violent Video Games on Aggressive Behavior, Aggressive Cognition, Aggressive Affect, Physiological Arousal, and Prosocial Behavior: A Meta-Analytic Review of the Scientific Literature," Psychological Science, Vol. 12, No. 5, 2001, pp. 353-359.

[48] L. Huesmann, "An Information Processing Model for the Development of Aggression," Aggressive Behavior, Vol. 14, No. 1, 1988, pp. 13-24.

[49] A. Schore, "The Experience-Dependent Maturation of a Regulatory System in the Orbital Prefrontal Cortex and the Origin of Developmental Psychopathology," Development and Psychopathology, Vol. 8, No. 1, 1996, pp. 59-87.

[50] L. Berkowitz, Frustrations, "Appraisals, and Aversively Stimulated Aggression," Aggressive Behavior, Vol. 14, No. 1, 1988, pp. 3-11.

[51] J. Yen, C. Ko, C. Yen, H. Wu and M. Yang, "The Comorbid Psychiatric Symptoms of Internet Addiction: Attention Deficit and Hyperactivity Disorder (ADHD), Depression, Social Phobia, and Hostility," Journal of Adolescent Health, Vol. 41, No. 1, 2007, pp. 93-98.

[52] C. Rohde and A. Kendle, "Report to English NatureHuman Well-being, Natural Landscapes and Wildlife in Urban Areas: A Review," Department of Horticulture and Landscape and the Research Institute for the Care of the Elderly, University of Reading, Bath, 1994.

[53] A. Stevens, "The Two Million-Year-Old Self," College Texas A\&M University Press, Station, 1993.

[54] S. Grof, "Beyond the Brain: Birth, Death and Transcendence in Psychotherapy," State University of New York, New York, 1985.

[55] C. Waddington, "The Evolution of an Evolutionist," Edinburgh University Press, Edinburgh, 1975. 